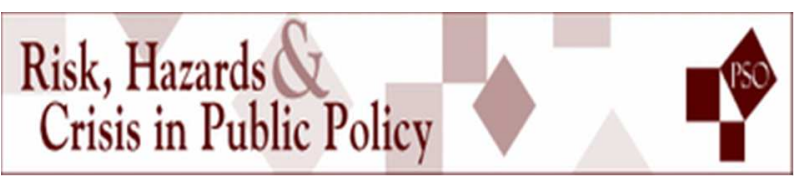

\title{
Taxonomy of the Crisis and Disaster Literature: Themes and Types in 34 years of Research
}

\begin{tabular}{|c|c|}
\hline Journal: & Risk, Hazards \& Crisis in Public Policy \\
\hline Manuscript ID & RHCPP-08-17-0131 \\
\hline Wiley - Manuscript type: & Original Article \\
\hline Keywords: & $\begin{array}{l}\text { Crisis Management, Disaster Planning and Preparedness, Emergency } \\
\text { Management and Response }\end{array}$ \\
\hline Abstract: & $\begin{array}{l}\text { This survey of the literature on crises and disasters reveals that crisis and } \\
\text { disaster scholars remain focused on 'classic' natural disaster types and on } \\
\text { our ability to prepare and respond to the threat they pose. The prevalence } \\
\text { of natural disasters as a crisis type and the dominance of preparedness as } \\
\text { a crisis theme indicates that the literature remains firmly linked to the } \\
\text { world of practice, examining how best practices may be shared to prepare } \\
\text { for future incidents. Yet interestingly, the three journals studied } \\
\text { demonstrate modest interest in a number of issues that are only likely to } \\
\text { increase in the coming years, all of which relate directly to an increasingly } \\
\text { interconnected world. Most notably, the lack of attention on system } \\
\text { interconnectedness or on advances in communication and cyber } \\
\text { dependence (despite the rise of social media and internet use) is a } \\
\text { surprising result, given how such systems and methods of communication } \\
\text { are becoming so integrated into daily life. Such studies could help scholars } \\
\text { and policy makers understand the unexpected turns crises can take and } \\
\text { provide practitioners with a range of tools when preparing for or handling } \\
\text { future crises. }\end{array}$ \\
\hline
\end{tabular}




\section{Taxonomy of the Crisis and Disaster Literature: Themes and Types in 34 years of Research}

Crises are a constant and to some extent inevitable phenomenon. Contrary to what is suggested in the introductions of many studies on crisis and disaster management, we do not live in an 'era of crisis'. Risks, hazards and crises have always been upon us. From the bubonic plague (mid-14 ${ }^{\text {th }}$ century) to the H1N1 swine flu pandemic (2009), from the Titanic (1912) to the Malaysia Airline disasters (2014), from the great London fire (1666) to the great Halifax explosion (1917) and the 911 WTC attacks (2001), disasters and crises are a reoccurring element throughout history. Today's political scandals and institutional crises pale in significance when compared to many decapitations and revolutions across the course of human history. Undoubtedly, we have become more urbanized, more tightly-coupled and we increasingly challenge the laws of gravity and motion with modern technology. Yet at the same time, as individuals, we are safer and healthier than ever before. ${ }^{1}$

Scholarly attention and focus when researching crises and disasters follows fashion. Major incidents that shock the world are likely to inspire research on a specific crisis type for the following years. Trends and new insights in academic thinking spark off new theoretical debates and thematic studies. This study sets out to report the shifts and patterns in crisis research across the past $30+$ years. Mapping crisis and disaster research reveals not only which topics and themes have received increasing or structural attention but also which ones perhaps deserve more study than they currently receive.

One thing is certain: overall, academic attention on crises and disasters has increased. As a rough measure, a topic search in Web of Science on 'crisis' yields less than 500 records annually before 1970 , then doubles to $1,000+$ records per year in the early 1980s, doubles again in the following decade (2,036 in 1993), takes fifteen years to double once more $(4,032$ in 2008) and only 8 years to almost triple in recent years (last count: 11,484 in 2016). The definition of crisis may vary widely between research areas as diverse as ecology, medicine, sociology and accountancy, but a topic search on 'disasters' reveals a similar exponential growth (<100 before 1980, doubled by 1990 , tripled by 2000, quadrupled by 2011 and in the most recent count ending 2016: 4,654 articles multiplication by a factor of 35 since 1980). ${ }^{2}$

Some pioneers deserve a specific mention. In 1963, Enrico Quarantelli, Russell Dynes and Eugene Haas established the now famous Disaster Research Center at Ohio State University, which in 1984 moved to Delaware. In the mid-1970s, the Natural Hazards Center in Boulder, Colorado was established (home to scholars such as Miletti, Tierney). Around the same time, Uriel Rosenthal, inspired by the oil crises of the 1970s, began his crisis research at Leiden University, joined later by Arjen Boin and Paul ' $t$ Hart. Major incidents such as those at Three Mile Island, Chernobyl and Bhopal in the mid-1980s gave rise to studies on man-made disasters and system complexity by Comfort,

\footnotetext{
${ }^{1}$ Max Roser (2017) - 'The short history of global living conditions and why it matters that we know it'. Published online at OurWorldInData.org. Retrieved from: https://ourworldindata.org/a-history-of-global-livingconditions-in-5-charts/ [Online Resource]. See for more information, the Institute for New Economic Thinking at Oxford University: http://www.inet.ox.ac.uk/people/view/39

${ }^{2}$ of course, one explanation is the explosive production growth in scholarly disciplines. Yet other topic searches, such as 'religion' or 'politics' reveal much less increase over time.
} 
Mittroff, Pauchant, Turner (a forerunner in the 1970s), Perrow, and Shrivastava. In response, in 1987, the Berkeley group (Weick, LaPorte, Roberts, Schulman, Roe) saw the light with their research focus on high reliability organizations. The first crisis and disaster researchers generated and integrated insights from a range of disciplines including sociology, political science, international relations, and organization studies. Standing on the shoulders of these giants, the crisis and disaster research community took off in subsequent decades.

This review of the crisis and disaster literature as published in three of the main specialized journals over the years will tell us which crisis types and theoretical themes received most attention and allow us to visualize shifts and trends. It will also reveal a relative lack of attention for contingencies that at the same time do seem a concern in practice. Our concluding section therefore has an agenda-setting character, suggesting avenues for further research.

\section{Design}

The analysis will include the results of codification of three independent specialized academic journals in the crisis and disaster research field. ${ }^{3}$ The International Journal of Mass Emergencies and Disasters (IJMED) has existed since 1983 and has a strong focus on natural disasters. IJMED is published by the International Research Committee on Disasters; Research Committee 39 of the International Sociological Association (ISA) and published three times per year. The Journal of Contingencies and Crisis Management (JCCM), established in 1993, casts the net wider and includes more political and organizational crises and perspectives. The journal Risk Hazards and Crisis in Public Policy (RHCPP, since 2010) casts a wider gaze across the spectrum of risks and crises - including natural and technological hazards, public health crises, terrorism, and societal and environmental disasters. Both JCCM and RHCPP are published by Wiley, with each volume containing four issues annually. In total, we have coded 1,493 articles in 226 issues over a time span of 34 years.

On average, the volumes of the journals contained 22 articles per year. Some volumes are particularly robust, but most journals also have a few lean years with only 12 to 15 articles per year. The graph below visualizes the fluctuation of absolute numbers of articles per year per journal since its creation.

>>Figure 1 Total number of articles per journal per year HERE<<

In the discussion of our findings we will look into the dynamics of the total attention for different themes and topics, but also more specifically at their relative share of the total.

\section{Methodological Approach}

\footnotetext{
${ }^{3}$ This is only a selection of the existing crisis and disaster journals. Others such as the journals: Australian Journal of Emergency Management; Disaster Management and Response; Disaster Prevention and Management; Disasters; International Journal of Disaster Risk Reduction; International Journal of Disaster Risk Science; International Journal of Emergency Management; Journal of Hazardous Materials; Journal of Homeland Security and Emergency Managent; Mass Emergencies; Natural Hazards; Natural Hazards Review; and Safety Science, to name a few, cover similar scholarly work, similar topics and similar years.
} 
In order to illustrate the shifts in academic attention within the field of crisis and disaster research, we elected to take a 'broad-brush' approach, focusing on counting the frequency of key terms within the article titles of each journal from their inception through to 2016. To do so, we first needed to develop a number of umbrella categories, under which to organize the codes for specific search terms. These were separated into 'types' and 'themes', each with its own set of umbrella categories (Table 1):

\begin{tabular}{|l|l|}
\hline Table 1: Umbrella Categories \\
\hline Crisis Types (10) & Crisis Themes (9) \\
\hline Armed Conflict/Humanitarian Aid & Risk \\
\hline Business & Preparedness \\
\hline Climate/Environment & Political leadership \\
\hline Critical Infrastructure & Crisis Communication \\
\hline Health & Decision Making \\
\hline ICT/Cyber & Organizing for Safety \\
\hline Natural Disasters & Community Resilience \\
\hline Riots/Crowds & Transboundary \\
\hline Terrorism & Aftermath \\
\hline Pollution/Toxic & \\
\hline
\end{tabular}

We began by examining the collective bibliographies of all three journals, picking out common terms and key words from both a thematic and crisis type perspective. The general pattern of these terms allowed us to create the categories above inductively, and as each term appeared it was organised under the most fitting umbrella category, resulting in a collection of 113 codes under crisis types and 111 under crisis themes. After the first round of coding, the umbrella categories were re-examined, with some being merged to solidify into the 19 in the table above.

Once the key terms were collected and organized, the article titles of all three journals were searched for each term, with the frequencies recorded by year. If any one article title contained multiple key terms that fell under a single umbrella term (eg. earthquake and flood, both of which fall under Natural Disasters), then only one was recorded, so as not to skew the overall results by coding a single article multiple times for the same theme or crisis type. However, if an article title contained three key terms, each of which fell under a different umbrella term, all three were recorded.

Once the frequencies of all key terms had been searched for RHCPP (the first journal tested), we reexamined its bibliography to see if any articles appeared that had not been covered by our search terms. In doing so, we discovered a number of un-coded articles that fell under the broader umbrella categories, but that had not been covered by our specific key terms. These articles were included in the aggregate count for each umbrella term. A number of un-coded articles also provided us with additional key terms, and this same process was repeated after coding both IJMED and JCCM (resulting in three main rounds of coding), and any new key terms were also retroactively searched for in those journals already examined. This process brought the total number of codes for crisis types to 117 and the total number for crisis themes to 118 .

Once the collective bibliographies of all three journals had been searched for all key terms, these were collected into an aggregate count per year under each umbrella term. Controlling for the 
different number of issues produced by the individual journals (with IJMED publishing 3 per year and both RHCPP and JCCM publishing 4), the results are examined in the following sections.

\section{Findings: Crisis Types}

The three journals differ slightly in their focus on the types of crises studied. JCCM, for example, has more articles on corporate crises and the role of businesses in crises than the other journals. It also consistently presents more studies on terrorism and critical infrastructures than the other two journals. RHCPP directs (relatively) more attention toward crisis types related to climate change, natural disasters and pollution. IJMED is characterized by its particular focus on natural disasters (more than $50 \%$ of its articles on average), an attention peak on terrorism in the 2000 s, and varying - even limited-attention on all other topics (see table 2).

\begin{tabular}{|l|r|r|r|}
\hline Table 2: Crisis Types per Journal & RHCPP & IJMED & JCCM \\
\hline Armed Conflict/Humanitarian Aid & $7 \%$ & $7 \%$ & $9 \%$ \\
\hline Business & $10 \%$ & $6 \%$ & $16 \%$ \\
\hline Climate/Environment & $24 \%$ & $5 \%$ & $5 \%$ \\
\hline Critical Infrastructure & $11 \%$ & $8 \%$ & $15 \%$ \\
\hline Health & $9 \%$ & $5 \%$ & $8 \%$ \\
\hline ICT/Cyber & $6 \%$ & $3 \%$ & $8 \%$ \\
\hline Natural Disasters & $15 \%$ & $51 \%$ & $17 \%$ \\
\hline Riots/Crowds & $0 \%$ & $2 \%$ & $5 \%$ \\
\hline Terrorism & $0 \%$ & $8 \%$ & $10 \%$ \\
\hline Pollution/Toxic & $18 \%$ & $4 \%$ & $7 \%$ \\
\hline
\end{tabular}

Figure 2 shows the results of how often particular crisis types were coded as part of the article titles in the period 1984-2016. Overall, we see that the most attention (in one third of the articles) in centered around natural disasters and the management of natural hazards, disaster response and disaster recovery. Perhaps unsurprisingly, the top three natural hazards covered across articles are earthquakes, floods and hurricanes. Other crisis types receive more or less equal shares of attention throughout the years: humanitarian aid and armed conflict; corporate crises; climate-related crises and risks; and pollution all score around $10 \%$ on average over the entire period. Cyber crises, terrorism, public health crises and riots or crowd issues receive the least attention (but still 2-5 articles annually, on average). One notable exception is the spike in attention on terrorism in the years immediately following 9/11 (in 2003 to be precise, which indicates a time lag of more than a year before empirical research was completed and published). There are no clear trends indicating increasing or decreasing attention over time for specific types of crisis.

>> Figure 2: Crisis Types, All Journals HERE << 
While there seems to be wide agreement that there is increasing cyber dependence and system connectedness, our scholarly attention has not risen concurrently in regards to this crisis domain. While terrorism has become front page news across many Western democracies (where most contributions to these journals come from - US, Western Europe, Australia), academic interest has subsided since the spike in research in the mid-2000s. Increasing mobility, waves of immigrants, urbanization and constant threats of mutating viruses and new virus agents gave rise to many global health risks and (potential) outbreaks that have not been increasingly addressed in the literature reviewed here. Either studies on these types of crises find their publication outlets in more specialized journals, or academic research is more driven by theoretical interests than the field (crisis and disasters) would suggest.

So, if the crisis types do not clearly govern the research agenda in a patterned way, what themes do we see over the years, and what preoccupations within the research does our analysis reveal? The next section discusses the themes we coded and the results we found across the lifespan of the three journals.

\section{Findings: Crisis Themes}

Again, the three journals vary slightly in their theoretical or thematic focus (table 3). RHCPP demonstrates a propensity towards publishing on risk governance when compared to the other two. Of the three, JCCM gives the most attention to an organizational perspective on crisis and safety with its emphasis on man-made disasters, high reliability organizations, safety culture and systemic risks. The other two journals (RHCPP and IJMED) indicate a greater focus on community resilience and citizen behavior. All three journals publish the most on what we have termed 'preparedness': the operational and practical organization of crisis and disaster mitigation, preparation, preparedness and response. These preferred topics reveal an orientation towards the world of practice.

\begin{tabular}{|l|r|r|r|}
\hline Table 3: Crisis Themes per Journal & RHCPP & IJMED & JCCM \\
\hline Risk & $24 \%$ & $11 \%$ & $9 \%$ \\
\hline Preparedness & $23 \%$ & $29 \%$ & $27 \%$ \\
\hline Political leadership & $6 \%$ & $4 \%$ & $3 \%$ \\
\hline Crisis Communication & $4 \%$ & $7 \%$ & $3 \%$ \\
\hline Decision Making & $3 \%$ & $4 \%$ & $5 \%$ \\
\hline Organizing for Safety & $8 \%$ & $8 \%$ & $21 \%$ \\
\hline Community Resilience & $23 \%$ & $27 \%$ & $18 \%$ \\
\hline Transboundary & $2 \%$ & $1 \%$ & $3 \%$ \\
\hline Aftermath & $6 \%$ & $9 \%$ & $12 \%$ \\
\hline
\end{tabular}

Figure 3 indicates how often themes were addressed as main topics (i.e. part of the article titles) in the crisis and disaster literature represented by these journals over the years. As suggested above, a robust part of the literature in the past decades covers 'preparedness' (28\% as average of the total number of articles), followed by community resilience (22\%). Within the emergency preparedness category, the greatest attention was directed toward planning, training and preparation, but also to operational emergency management and more specific response measures such as evacuation. Community resilience pertains to citizen involvement when disaster strikes, post-crisis recovery, and 
to vulnerable communities. These codes link nicely to the most recurrent crisis type (natural disasters) addressed in the literature. Attention for organizational perspectives on safety increased considerably during the 1990s and subsided somewhat after 2001.

>> Figure 3: Crisis Themes, All Journals HERE $<<$

The political dimensions of crisis management may have become more important (Boin et al, 2016), this trend does not translate into a rising number of articles with political leadership as their primary topic. Also, in spite of the many developments in media technology and online citizen involvement during and after crises, crisis communication does not appear more often as a main theme in the coded article titles. The increasing likelihood of transboundary or cross-sectoral crises is also not reflected within the research agenda of any of the three journals, as indicated by the lack of focus in published work throughout the years. The next section will reflect on avenues for future research, based on our findings above.

\section{Summary of Findings}

As evidenced in the results above, the literature on crises and disasters remains focused around 'classic' natural disaster types and our ability to prepare and respond to the threat they pose. The prevalence of natural disasters as a crisis type and the dominance of preparedness as a crisis theme indicates that the literature remains firmly linked to the world of practice, examining how best practices may be shared to prepare for future incidents. Yet interestingly, the collective literature so far appears to demonstrate modest interest in a number of issues that are only likely to increase in the coming years, all of which relate directly to an increasingly interconnected world. Most notably, the lack of attention on system interconnectedness or on advances in communication and cyber dependence (despite the rise of social media and internet use) is a surprising result, given how such systems and methods of communication are becoming so integrated into daily life. Such studies could help scholars and policy makers understand the unexpected turns crises can take and provide practitioners with a range of tools when preparing for or handling future crises (cf. 't Hart and Sundelius, 2013).

\section{Looking Back, Moving Forward: A Research Agenda}

It would be too easy to say we should just pay more attention to those topics and approaches that remain relatively under-emphasized given the findings above. The themes and crises that were particularly unaddressed may have not at all been scored for that very same reason: our collective lack of awareness of their importance. Nonetheless, a few themes come to mind, and they all seem related to our increasing interconnectedness:

Networked crisis management 
Networks are receiving increasing attention as a common mode of governance, and many authors point out that crisis and disaster management is by definition a network activity among partners from different disciplines, policy domains and jurisdictions. Yet the articles that approach crisis and disaster management from a network perspective are relatively few and far between (Waugh and Streib, 2006; Kapucu 2008; Moynihan, 2009; Wimelius and Engberg, 2015). Meanwhile, identifying complicating factors in collaborative governance under conditions of uncertainty and urgency, or best practices in coordination between partners that are not hierarchically related or relatively unfamiliar with each other's way of working, seem to be of vital importance for improving crisis and disaster response.

\section{Cascading effects of interdependencies}

In this literature review we have coded how many articles address the transboundary nature of crisis and disaster management, regardless of whether the crisis itself was cross-sectoral, transnational or another form of boundary spanning. What we see is that many articles touch upon the systemic interdependencies and cascading effects that complicate crises and crisis management, yet do not address it as a core theme. Ansell et al (2010) focused on Thompson's classic (1967) distinction between pooled, sequential and reciprocal interdependencies in discussing why transboundary crises are so challenging in terms of sharing information, allocating and exchanging resources and coordinating communication. The same interdependencies could also be helpful when identifying why some crises escalate or spillover in the first place, and whether we can forecast the 'transboundary' potential of any particular incident or vulnerability.

\section{Self-organization among citizens}

While communication technology increasingly enables citizens to inform themselves, share information, warn and help others and exchange essential resources during crises and disasters, the study of the use of social media seems to focus mainly on the government-citizen communication aspect. This classic relation between government and citizens has undoubtedly changed because of social media, but many other trends seem under-studied (as also argued by Wukich and Steinberg, 2013). Initiatives such as facebook disaster maps (https://research.fb.com/facebook-disaster-mapsmethodology/), or the work of volunteer and technical communities in tracing the Malaysian Airlines MH370 debris have been studied from the perspective of information systems, but not so much as a new trend influencing crisis governance. How do new possibilities and crowd sourcing initiatives that produce information in a rapid but dispersed way impact the management of crises and disasters, and the way government organizations or NGOs deal with information?

\section{Use of Big Data in crisis research}

Relatedly, not only citizens use big data. Increasingly citizens are data carriers themselves, enabling authorities to monitor and trace crowd movements and migration patterns, detect anomalies and forensically investigate evidence. Algorithms may find patterns and causalities related to a variety of regularly occurring incidents such as fires, traffic accidents, riots and violent outbursts, reputation threats, or disease outbreaks. The use of the 'Fourth Paradigm' in the crisis literature analyzed here has been limited so far (Cf. Hey, Tansley and Tolle, 2009). Some research communities may 'mine' the big data potential in crisis management much faster and more diligently than others-consider the sheer numbers of incidents and related data in countries such as China or India, combined with 
the existing expertise in analyzing this data. The results could reveal important new insights and the next generation of ground-breaking crisis researchers may be pre-dominantly non-Western.

It is about time that different worlds of research and practice meet. The collision or integration of varied perspectives will yield new and exciting knowledge to prepare us for the crises and disasters of the future. Each of the above could constitute a special issue for one of the journals analyzed in this study. We can only hope the scholarly community will accept the challenges ahead and we look forward to learning about it.

\section{References}

Ansell, Chris, Arjen Boin and Ann Keller (2010) "Managing Transboundary Crises: Identifying Building Blocks of an Effective Response System." Journal of Contingencies and Crisis Management 18 (4): 205-17

Boin, Arjen, Paul 't Hart, Eric Stern and Bengt Sundelius (2016) The Politics of Crisis Management: Public Leadership Under Pressure, Cambridge University Press, $2^{\text {nd }}$ edition.

Hey, Tony, Stewart Tansley and Kristin Tolle, (eds.)(2009) The Fourth Paradigm: data-Instensive Scientific Discovery, Redmond, WA: Microsoft Research.

Kapucu, Naim (2008), 'Collaborative Emergency Management: Better Community Organising, Better Public Preparedness and Response', Disasters, Volume 32, Number 2, pp. 239-262.

Moynihan, Donald P. (2009), The Network Governance of Crisis Response: Case Studies of Incident Command Systems', Journal of Public Administration Research, Volume 19, Number 4, pp. 895-915.

't Hart, Paul and Bengt Sundelius (2013) 'Crisis management revisited: A new agenda for research, training and capacity building within Europe', Cooperation and Conflict, 48: 444-461.

Thompson, J.D. (1967) Organizations In Action, New York: McGraw-Hill.

Waugh, William L. Jr. and Gregory Streib (2006), 'Collaboration and Leadership for Effective Emergency Management', Public Administration Review, Volume 66, pp. 131-140.

Wimelius, Malin and Jan Engberg (2015) Crisis Management through Network Coordination: Experiences of Swedish Civil Defence Directors, Journal of Contingencies and Crisis Management, 23(3), 129-137.

Wukich, Clayton and Alan Steinberg (2013) Nonprofit and Public Sector Participation in SelfOrganizing Information Networks: Twitter Hashtag and Trending Topic Use During Disasters, Risk, Hazards and Crises in Public Policy, 4(2), 84-109. 
Page 9 of 11

Risk, Hazards \& Crisis in Public Policy

Figure 1 Total number of articles per journal per year

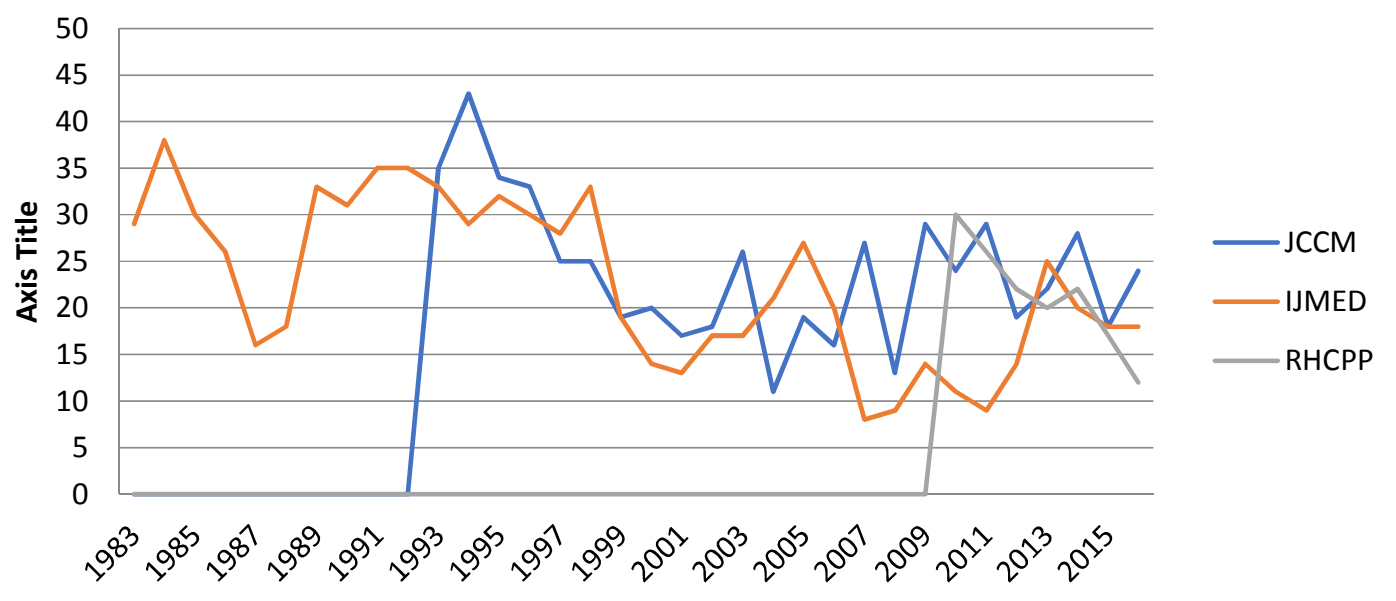




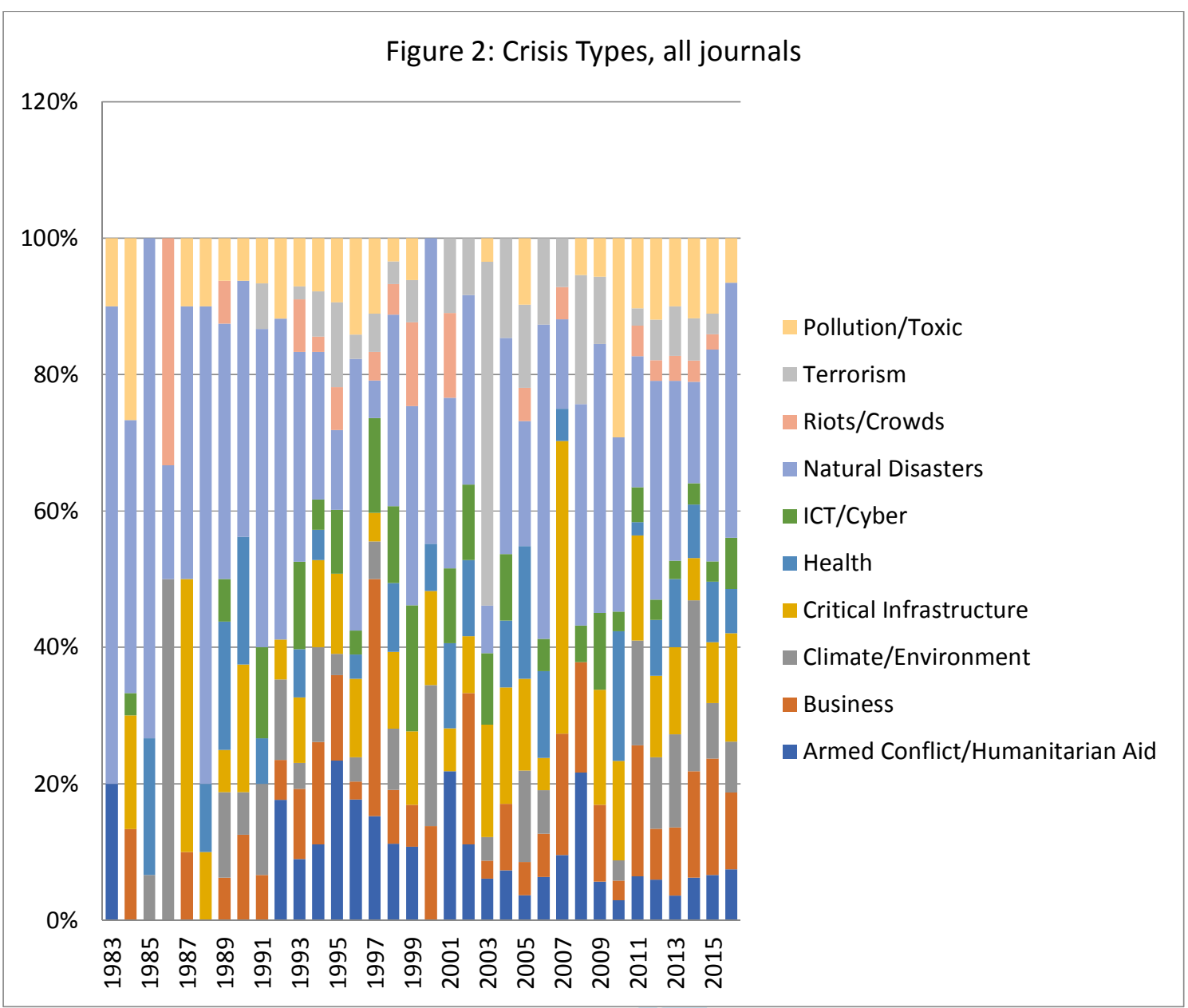


Figure 3: Crisis Themes, All Journals

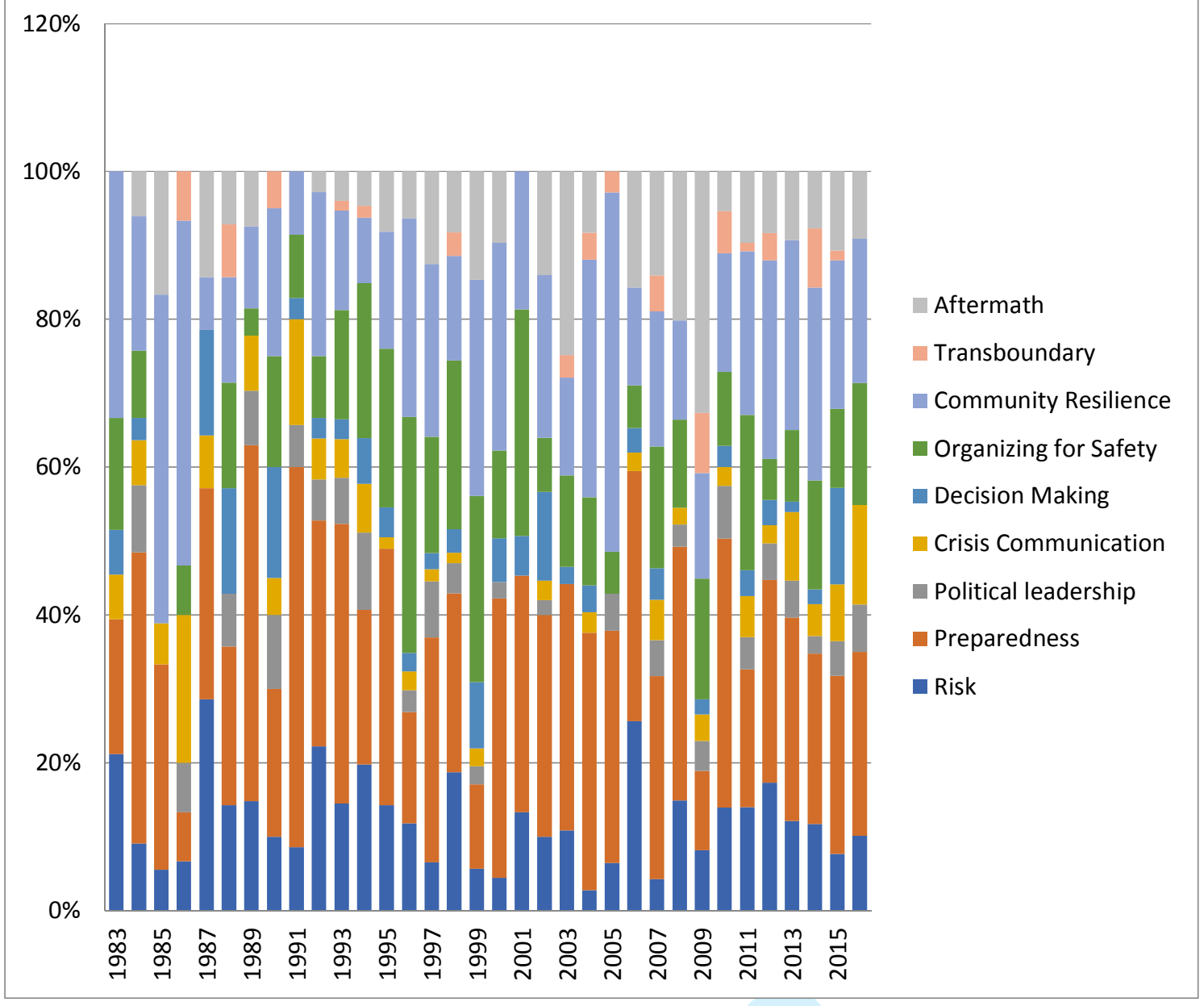

